\title{
Improvement of aerosol optical depth retrieval over Hong Kong from a geostationary meteorological satellite using critical reflectance with background optical depth correction
}

\author{
Mijin Kim ${ }^{a}$, Jhoon Kim ${ }^{\text {a,* }}$, Man Sing Wong ${ }^{b}$, Jongmin Yoon ${ }^{c}$, Jaehwa Lee ${ }^{\text {d,e }}$, Dong Wu ${ }^{\text {e }}$ P.W. Chan ${ }^{\text {, }}$, \\ Janet E. Nichol ${ }^{\mathrm{b}}$, Chu-Yong Chung ${ }^{\mathrm{g}}$, Mi-Lim Ou ${ }^{\mathrm{h}}$ \\ ${ }^{a}$ Department of Atmosphere Sciences/IEAA BK21, Yonsei University, Seoul, Republic of Korea \\ b Department of Land Surveying and Geo-Informatics, The Hong Kong Polytechnic University, Hung Hom, Kowloon, Hong Kong \\ c Atmospheric Chemistry Department, Max-Planck-Institute for Chemistry (Otto Hahn Institute), Hahn-Meitner-Weg 1, D-55128 Mainz, Germany \\ d Earth System Science Interdisciplinary Center, University of Maryland College Park, College Park, MD, USA \\ e NASA Goddard Space Flight Center, Greenbelt, MD, USA \\ ${ }^{\mathrm{f}}$ Hong Kong Observatory, 134A Nathan Road, Hong Kong \\ ' National Meteorological Satellite Center, Republic of Korea \\ h National Institute of Meteorological Research, Republic of Korea
}

\section{A R T I C L E I N F O}

\section{Article history:}

Received 30 May 2013

Received in revised form 8 December 2013

Accepted 10 December 2013

Available online 28 December 2013

\section{Keywords:}

Remote sensing

Algorithm

Aerosol optical depth

Critical reflectance

Background aerosol optical depth

Geostationary

\begin{abstract}
A B S T R A C T
Despite continuous efforts to retrieve aerosol optical depth (AOD) using a conventional 5-channel meteorological imager in geostationary orbit, the accuracy in urban areas has been poorer than other areas primarily due to complex urban surface properties and mixed aerosol types from different emission sources. The two largest error sources in aerosol retrieval have been aerosol type selection and surface reflectance. In selecting the aerosol type from a single visible channel, the season-dependent aerosol optical properties were adopted from longterm measurements of Aerosol Robotic Network (AERONET) sun-photometers. With the aerosol optical properties obtained from the AERONET inversion data, look-up tables were calculated by using a radiative transfer code: the Second Simulation of the Satellite Signal in the Solar Spectrum (6S). Surface reflectance was estimated using the clear sky composite method, a widely used technique for geostationary retrievals. Over East Asia, the AOD retrieved from the Meteorological Imager showed good agreement, although the values were affected by cloud contamination errors. However, the conventional retrieval of the AOD over Hong Kong was largely underestimated due to the lack of information on the aerosol type and surface properties. To detect spatial and temporal variation of aerosol type over the area, the critical reflectance method, a technique to retrieve single scattering albedo (SSA), was applied. Additionally, the background aerosol effect was corrected to improve the accuracy of the surface reflectance over Hong Kong. The AOD retrieved from a modified algorithm was compared to the collocated data measured by AERONET in Hong Kong. The comparison showed that the new aerosol type selection using the critical reflectance and the corrected surface reflectance significantly improved the accuracy of AODs in Hong Kong areas, with a correlation coefficient increase from 0.65 to 0.76 and a regression line change from $\tau_{\text {MI [basic algorithm] }}=0.41 \tau_{\text {AERONET }}+0.16$ to $\tau_{\text {MI [new algorithm] }}=0.70 \tau_{\text {AERONET }}+0.01$.
\end{abstract}

(c) 2013 Elsevier Inc. All rights reserved.

\section{Introduction}

It is well-known that aerosols play a crucial role in air quality and climate change (e.g. Haywood \& Shine, 1995; IPCC, 2007). Therefore, numerous aerosol retrieval algorithms utilizing satellite measurements have been developed for both low earth orbit (LEO) (Diner et al., 2001; Higurashi \& Nakajima, 1999; Hsu, Tsay, King, \& Herman, 2004; Kaufman et al., 1997; Kim et al., 2007; Lee, Kim, Song, Ryu, et al.,

\footnotetext{
* Corresponding author at: Institute of Earth, Astronomy, and Atmosphere, Brain Korea 21 Program, Department of Atmospheric Sciences, Yonsei University, Seoul, Republic of Korea. Tel.: +822 2123 5682; fax: +82 23655163 .

E-mail address: jkim2@yonsei.ac.kr (J. Kim).
}

2010; Mishchenko et al., 1999; Remer et al., 2005; Tanre, Kaufman, Herman, \& Mattoo, 1997; Torres, Bhartia, Herman, Ahmad, \& Gleason, 1998; Torres et al., 2007; von Hoyningen-Huene, Freitag, \& Burrows, 2003; Wong, Lee, Nichol, \& Li, 2010) and geostationary orbit (GEO) (Kim, Yoon, Ahn, Sohn, \& Lim, 2008; Knapp, Vonder Haar, \& Kaufman, 2002; Urm \& Shon, 2005; Wang et al., 2003). The basic principle of aerosol optical depth (AOD) retrieval is to separate the reflectance by aerosol from the total signal sent to the satellite including reflectance from the surface and atmosphere, where the estimation of surface reflectance is one of the most important error sources. In order to obtain the surface reflectance, Kaufman et al. (1997) suggested the dense dark vegetation (DDV) method for the MODIS operational algorithm (known as Collection 4), and Remer et al. (2005) used the correlations between the 
reflectances in the visible channels and shortwave-IR channel at $2.1 \mu \mathrm{m}$. von Hoyningen-Huene et al. (2003) used the normalized difference vegetation index (NDVI), and Levy, Remer, Mattoo, Vermote, and Kaufman (2007) developed the second generation MODIS operation algorithm (known as Collection 5.1) by making use of the NDVI to determine the correlations suggested by Remer et al. (2005) for each pixel. With limited channels from the geostationary orbit, the clear sky composite technique has been widely used for aerosol retrieval (Kim et al., 2008; Knapp et al., 2002; Wang et al., 2003; Yoon et al., 2007). Lee, Kim, Song, Ryu, et al. (2010) adopted the method over turbid water for aerosol retrieval from the Geostationary Ocean Color Imager (GOCI), and Wong et al. (2010) used the method for high spatial resolution retrieval of the AOD from MODIS.

Continuous AOD monitoring is important for estimating the aerosol emission and air quality change over urban areas, which have critical effects on human health in heavily populated areas. Since AOD is often used as a linear estimator for fine particulate matter (PM2.5) (e.g., Liu et al. 2004; Wang et al., 2003), biased AOD measurements can lead to systematic errors in monitoring and forecasting PM2.5. However, there have been limited studies on the retrieval of AOD focused on localized urban areas [e.g., Castanho et al., 2007; Oo et al., 2010; Wong, Nichol, \& Lee, 2011] due to the difficulty in handling the bright and heterogeneous nature of urban surfaces. Castanho et al. (2007) and Oo et al. (2010) showed that globally defined ratios of visible to shortwave-IR reflectance in the MODIS Collection 5 operational algorithm used to estimate surface reflectance are significantly underestimated for urban areas and lead to a large offset $\left(\tau_{\text {MODIS }}=0.91 \tau_{\text {AERONET }}+0.33\right.$, $R^{2}=0.66$ ) in Mexico City (Castanho et al., 2007) and a positive bias $\left(\tau_{\text {MODIS }}=1.24 \tau_{\text {AERONET }}+0.11, R^{2}=0.85\right)$ in New York City (Oo et al., 2010). These studies demonstrated that the new reflectance ratio of visible to shortwave-IR obtained for the urban areas led to a great improvement in the agreement between the MODIS and AERONET AOD results. Wong et al. (2011) showed that considering the complex and heterogeneous surface properties over Hong Kong by increasing the spatial resolution to $500 \mathrm{~m}$ improved the underestimation problem in the MODIS C005 AOD product. In the study, the slope of the linear regression between the AODs from the MODIS and AERONET was increased from 0.75 to 0.83 .

In addition to the importance of accuracy in surface reflectance, the determination of the aerosol type is also an important factor in the aerosol retrieval algorithm. According to Zhang, Christopher, and Holben (2001), the uncertainty due to surface reflectance by $1 \%$ results in a $10 \%$ error in the AOD for small AODs $(\tau=0.5)$, and a perturbation in SSA by $\pm 3 \%$ with respect to the reference value of 0.90 results in a $10 \%$ error for small AODs $(\tau=0.5)$ and a 32\% error for large AODs $(\tau=1.5)$. Therefore, the rapid change in the aerosol optical type due to the mixture of emission sources over urban areas both spatially and temporally is another important error source in AOD retrieval, especially for the single visible channel algorithm, which has limitations in selecting the aerosol type.

A single visible channel from the Meteorological Imager (MI) onboard the Communication, Ocean, and Meteorological Satellite (COMS), the first Korean geostationary multi-purpose satellite, can be utilized to retrieve the AOD at high temporal and spatial resolutions of 30 min and $1 \mathrm{~km}$, respectively. Previously, a geostationary single channel algorithm to retrieve AOD was developed for East Asia (Yoon et al., 2007) with the clear sky composite method. Then, Kim et al. (2008) improved the algorithm by applying the mid-IR channel at $3.7 \mu \mathrm{m}$, in addition to the conventional visible channel, to obtain more accurate surface reflectance. In the previous study, the retrieved AOD was compared with the values from AERONET showing the linear regression $\tau_{\text {MTSAT-1R }}=0.93 \tau_{\text {AERONET }}+0.21$, with $R^{2}=0.52$, at Anmyeon, Korea, for the period from February to March 2006. Although the algorithm showed the potential in retrieving accurate AODs from geostationary satellites, it still has a limitation for monitoring urban aerosol due to the fact that the usage of the mid-IR channel is restricted to areas over dark vegetation. Thus, the objective of this study is the improvement of AOD retrieval accuracy over the urban area of Hong Kong.

Due to the steady loading of pollutants in Hong Kong, background aerosols have caused a bias in estimating the surface reflectance, as found by Knapp et al. (2002). When the background aerosol optical depth (BOD) was ignored or underestimated, less aerosol scattering was removed from the measured top-of-atmosphere (TOA) reflectance, resulting in an underestimation of the retrieved AOD. Yoon (2006) showed that the general BOD value of the all AERONET AODs [670 nm] in 2001 was less than 0.4 and the values resulted in $40 \%$ error of surface reflectance in the clear sky composite method. From these results, monthly-analyzed BOD over Hong Kong in this study was considered to improve the accuracy of surface reflectance.

Furthermore, the critical reflectance method was adopted to select the proper aerosol type, while only the continental aerosol type in the radiative transfer model, $6 \mathrm{~S}$, was assumed in the previous studies. The surface reflectance for which a change of AOD does not change the TOA reflectance was defined as critical reflectance, showing a one-toone relationship with the aerosol SSA (Fraser \& Kaufman, 1985). Since the critical reflectance can be obtained even from single-channel reflectance, this method is very valuable for the geostationary algorithm. For this study, the aerosol optical properties for five SSA conditions were optimized over East Asia by extensive inversion data at selected AERONET sites and applied to calculate look-up tables (LUTs). The newly retrieved AODs were compared with those from the AERONET measurements over the Hong Kong area. With the capability of geostationary satellites for hourly global coverage, this improved algorithm was expected to contribute to the monitoring of aerosol events and the comparison of numerical model results.

\section{Aerosol optical depth retrieval algorithm}

In this study, basically, a single visible channel algorithm was developed to monitor the long-range transport of aerosol over East Asia with geostationary measurement, based on the general LUT approach. In calculating LUTs, the dynamic aerosol optical model was constructed in order to allow a mode radius change in volume size distribution with respect to the AOD and SSA, which was compiled for each season. Then, one of the LUTs was selected in the inversion process depending on the conditions of the measurement. The clear sky composite method was adopted for the basic algorithm with an assumption that BOD is 0 .

The algorithm was modified for AOD retrieval in the localized urban area of Hong Kong, with new features: the BOD correction was newly added to consider the persistent aerosol loading in the urban area, and the critical reflectance was applied to select the appropriate aerosol type in real time over Hong Kong. To calculate the LUTs for the critical reflectance method, five-aerosol models were newly constructed from AERONET inversion data for different bins of SSA. The clear sky composite method, which is still a good approach for urban areas with less variable surface conditions than other areas over time, was also used to obtain surface reflectance.

Fig. 1 shows the flowchart of the AOD retrieval algorithm with the above-mentioned new features. The MI provides the single visible reflectance $(0.55-0.80 \mu \mathrm{m})$ in $1 \mathrm{~km}$ spatial resolution and the brightness temperature (BT) at four IR channels in $4 \mathrm{~km}$ resolution. The band ranges for those IR channels were 10.3-11.3 $\mu \mathrm{m}, 11.5-12.5 \mu \mathrm{m}, 6.5-$ $7.0 \mu \mathrm{m}$, and 3.5-4.0 $\mu \mathrm{m}$, respectively. To simultaneously use the BT and the visible reflectance in cloud detection, the visible reflectance was resampled at a resolution of $4 \mathrm{~km}$.

The AOD was only retrieved for cloud-free pixels by comparing the simulated and measured TOA reflectance values. In the algorithm, cloud pixels were detected and masked out first using an integrated methodology including threshold tests that detect bright and cold clouds. In this methodology, a threshold of 0.28 for the TOA reflectance at visible channels separates the bright cloud pixels, and a threshold of $5 \mathrm{~K}$ for the BT difference between the maximum BT for the previous 


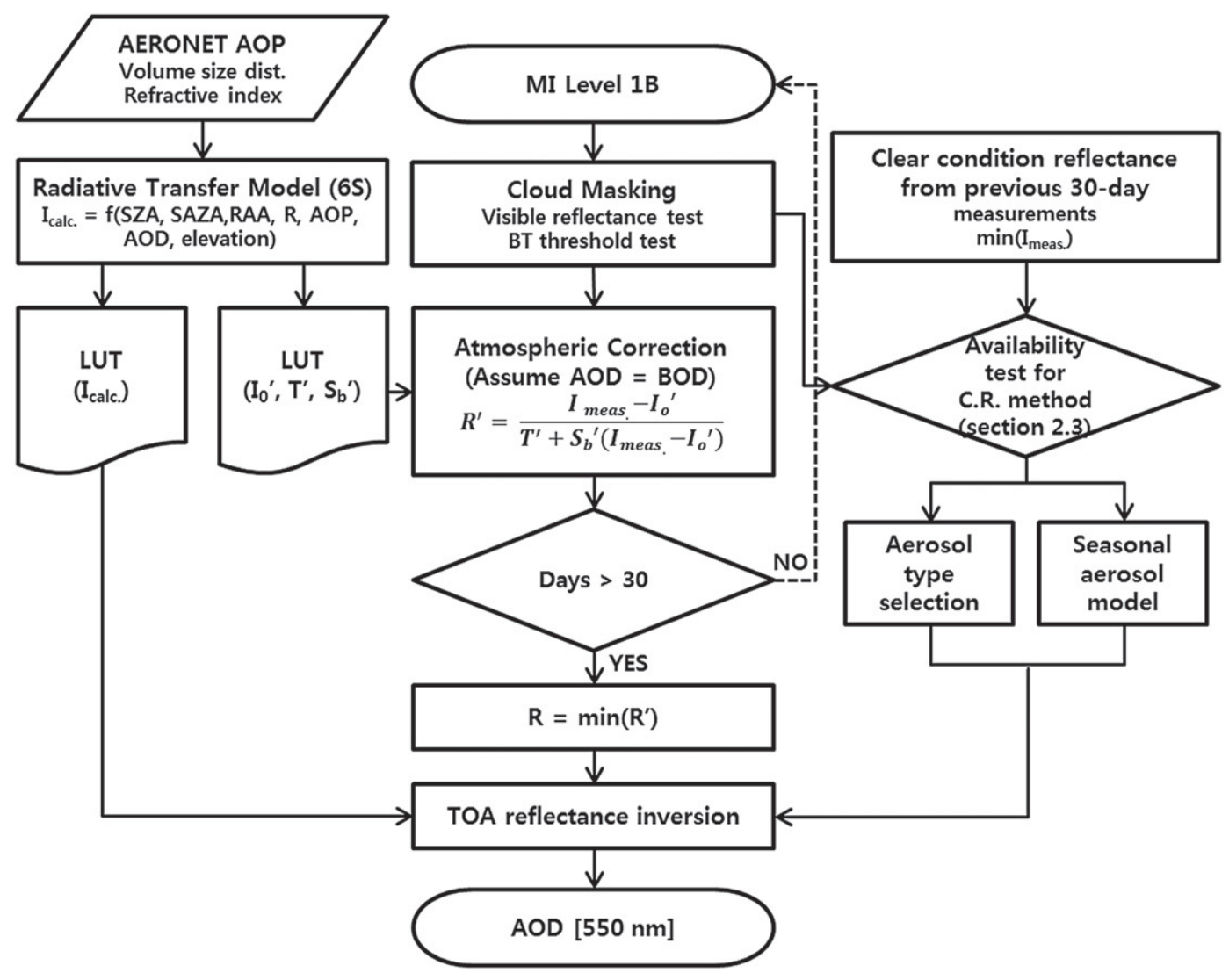

Fig. 1. Flowchart of the AOD retrieval algorithm using the single visible channel of the MI.

30 days and the BT of the current pixel value separates the cold cloud pixels. The maximum BT at the IR1 channel for each pixel was regarded as clear conditions without clouds or aerosol by an assumption that a cloud pixel is colder than a clear pixel. However, this method has several uncertainties for each season. During winter, the low temperature of the snow surface can result in incorrect detection of clear pixels. During spring and autumn, the increasing and decreasing trends of the surface temperature can lead to the underestimation and overestimation of cloud detection, respectively. During the summer monsoon season, the lack of clear conditions may cause an error in cloud detection as well. After cloud masking, the AOD was retrieved by the LUT approach.

Over the Hong Kong area, surface reflectance was calculated with the BOD correction, which will be mentioned later in Section 2.5. On the other hand, the aerosol type was selected by using the obtained critical reflectance value according to the precalculated relationship between the critical reflectance and SSA when the pixels satisfied the availability test, as described in Section 2.3. For the remaining pixels where the availability test was not satisfied, the aerosol property optimized for Hong Kong was assumed.

Hereafter, each part of the study is described in detail. After a description of the methodology of the basic algorithm, a description of the improved methodologies, the usage of the critical reflectance method, and the BOD correction follow.

\subsection{Aerosol optical properties over East Asia}

The calculation of the LUT with a well-defined aerosol model is critical in order to obtain an accurate AOD value, because the measured TOA reflectance is significantly affected by the amount and microphysical properties of aerosol. Therefore, extensive AERONET inversion data over East Asia $\left(20^{\circ} \mathrm{N}-50^{\circ} \mathrm{N}, 95^{\circ} \mathrm{E}-145^{\circ} \mathrm{E}\right)$ (Dubovik \& King, 2000;
Dubovik et al., 2000) were analyzed to obtain the optimized aerosol model for East Asia. Table 1 lists the details for the AERONET sites used, where 4898 datasets were compiled over 11 years, from 1999 to 2010.

Fig. 2 shows the seasonal mean of the volume size distribution, and Table 2 lists the refractive index data obtained from the selected AERONET sites over the study period. The seasonal aerosol optical properties were analyzed in order to consider the changes in the emission sources and meteorological conditions. As shown in Fig. 2, fine-mode particles of the bi-modal lognormal size distribution were dominant except in the spring, when frequent dust events lead to an increase in coarse-mode particles over East Asia. As Lee, Kim, Song, Kim, et al. (2010) suggested, the most frequently detected aerosol type over East Asia is black carbon (BC). The refractive indices represented in Table 2 are close to those of the absorbing aerosol (Lee, Kim, Song, Ryu, et al., 2010). The obtained AERONET dataset shows that the mode radius tends to change with increases in the AOD and SSA. With respect to seasonal variations, SSA increased during the summer due to the hygroscopic growth of the aerosol in humid conditions, while the SSA decreased during the winter due to the large amount of $\mathrm{BC}$ emissions from heating sources. The seasonal SSAs at $675 \mathrm{~nm}$ for different AOD bins are listed in Table 2, with averages of 0.92, 0.94, 0.92, and 0.91 for spring (MAM), summer (JJA), autumn (SON), and winter (DJF), respectively. As AOD increased, the SSA increased from 0.91 to $0.95,0.92$ to $0.96,0.90$ to 0.94 , and 0.88 to 0.93 for each season in the same order as above.

\subsection{Calculation of the look-up table}

With the obtained aerosol model from the analysis of the AERONET inversion data, the seasonal LUTs were calculated using a radiative transfer code: 6S (Second Simulation of the Satellite Signal in the Solar 
Table 1

The list of the AERONET sites used to analyze the long-term aerosol optical properties.

\begin{tabular}{|c|c|c|c|c|}
\hline Site & Number of data & Latitude $\left({ }^{\circ} \mathrm{N}\right)$ & Longitude $\left({ }^{\circ} \mathrm{E}\right)$ & Data period \\
\hline Anmyeon & 543 & 36.539 & 126.33 & 1999-2007 \\
\hline Bac_Giang & 314 & 21.291 & 106.225 & 2003-2009 \\
\hline Beijing & 906 & 39.977 & 116.381 & $2001-2007$ \\
\hline Chen-Kung_Univ & 309 & 23 & 120.217 & $2002-2010$ \\
\hline Dongsha_Island & 48 & 20.699 & 116.729 & 2004-2010 \\
\hline EPA-NCU & 248 & 24.968 & 121.185 & 2006-2010 \\
\hline Gosan_SNU & 193 & 33.292 & 126.162 & 2001-2010 \\
\hline Gwangju_K-JIST & 217 & 35.228 & 126.843 & 2004-2009 \\
\hline Hong_Kong_Hok_Tsui & 119 & 22.21 & 114.258 & $2007-2010$ \\
\hline Hong_Kong_PolyU & 86 & 22.303 & 114.18 & $2005-2010$ \\
\hline Inner_Mongolia & 11 & 42.683 & 115.954 & $2001-2001$ \\
\hline Lulin & 67 & 23.469 & 120.874 & 2007-2010 \\
\hline Osaka & 286 & 34.651 & 135.591 & 2001-2008 \\
\hline Seoul_SNU & 87 & 37.458 & 126.951 & 2000-2003 \\
\hline Shirahama & 1050 & 33.693 & 135.357 & $2000-2010$ \\
\hline Taichung & 13 & 24.106 & 120.491 & 2005-2005 \\
\hline Taipei_CWB & 293 & 25.03 & 121.5 & $2002-2010$ \\
\hline Ussuriysk & 108 & 43.7 & 132.163 & 2004-2010 \\
\hline
\end{tabular}

Spectrum) (Vermote, Tanre, Deuze, Herman, \& Morcrette, 1997). The 6S has been widely used in satellite remote sensing including the LUT for the MODIS atmospheric correction algorithm. As the measured TOA reflectance consists of scattering from the surface reflectance and the atmosphere including aerosol, the TOA reflectance was calculated and constructed as a LUT as a function of the AOD, the optical property of aerosol, the geometry of the sun and satellite, and the surface conditions. Table 3 shows the ranges of variables used to calculate the LUT. The numbers of entries were selected carefully to save computing time and to maintain the required accuracy. The calculated TOA reflectance was interpolated linearly between the neighboring bins for geometry, AOD, surface reflectance, and elevation. The surface topography and US62 standard atmosphere (McClatchey, Fenn, Selby, Volz, \&
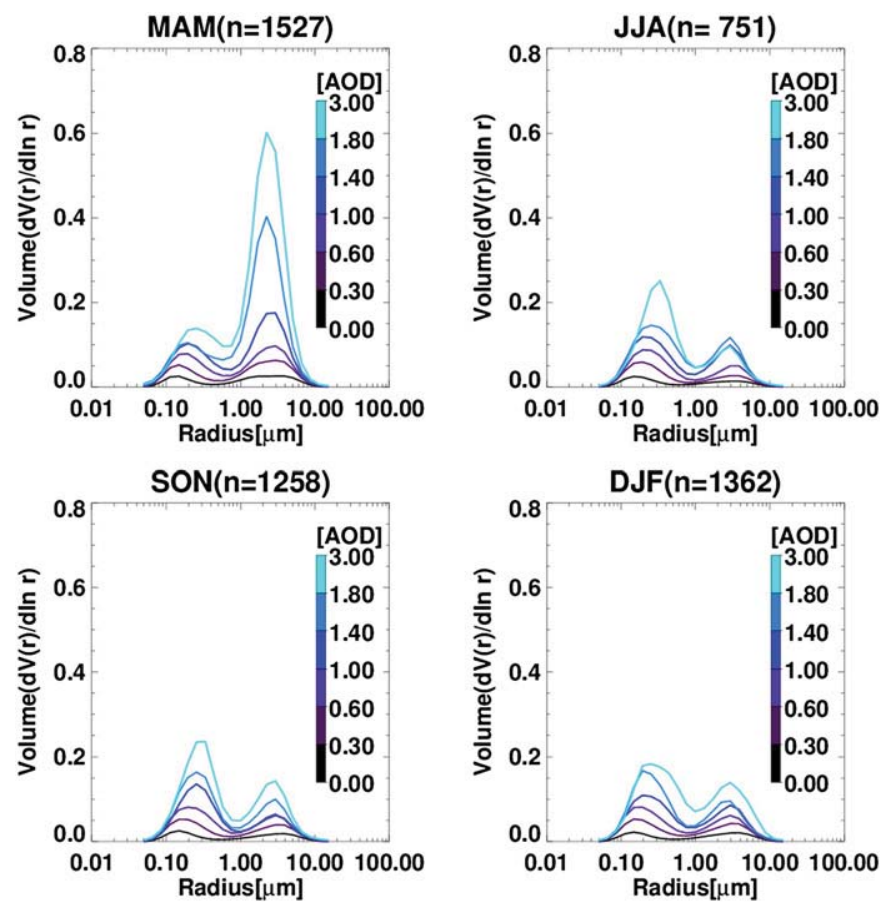

Fig. 2. The volume size distribution for each season obtained from the AERONET inversion data listed in Table 1 . The size distributions are averaged for each AOD interval, and the color of the curve indicates the mean AOD value.
Garing, 1972) were considered to be parameters to correct Rayleigh scattering.

\subsection{Critical reflectance method}

In the case of Hong Kong, the diversity of aerosol particles from different sources influences the retrieval of AOD (Wong, Nichol, \& Lee, 2013). The air quality over the area is influenced by various sources from continents, industrialized regions, and oceans depending on the wind direction. The average SSA at $675 \mathrm{~nm}$ obtained from AERONET inversion data over the area changed as follows: (1) 0.90 for spring, (2) 0.92 for summer, (3) 0.91 for autumn, and (4) 0.90 for winter. In gener$\mathrm{al}$, the occurrence of BC emissions over South Asia is significantly higher than that over North Asia (Lee, Kim, Song, Kim, et al., 2010). Thus, SSA for each season over Hong Kong is systematically lower than the analyzed value for East Asia, as shown in Section 2.1. For this reason, the aerosol property for East Asia does not represent the aerosol properties in Hong Kong. Furthermore, with the heavy traffic and large population in Hong Kong, the source of aerosol changes diurnally and seasonally, so the selection of the proper aerosol type over the Hong Kong area has a crucial role in AOD retrieval. Therefore, critical reflectance was introduced in order to define the aerosol types over Hong Kong.

The critical reflectance occurs when the backscattering effect of aerosol is balanced with the absorbing effect (Wells, Martins, Remer, Kreidenweis, \& Stephens, 2012). Over the bright surface, the increase

Table 2

The refractive index and SSA at $675 \mathrm{~nm}$ for each seasonal aerosol type obtained from the AERONET inversion data (MAM: March, April May; JJA: June, July, August; SON: September, October, November; DJF: December, January, February).

\begin{tabular}{clllllll}
\hline & & AOD & & & & \\
\cline { 3 - 8 } & & 0.15 & 0.45 & 0.8 & 1.2 & 1.6 & $>2.6$ \\
\hline Refractive index [real] & MAM & 1.47 & 1.47 & 1.47 & 1.49 & 1.53 & 1.52 \\
at 675 nm & JJA & 1.41 & 1.42 & 1.44 & 1.46 & 1.46 & 1.45 \\
& SON & 1.43 & 1.44 & 1.45 & 1.44 & 1.46 & 1.47 \\
Refractive index & DJF & 1.45 & 1.46 & 1.47 & 1.49 & 1.48 & 1.50 \\
[imaginary] & MAM & 0.0084 & 0.0073 & 0.0074 & 0.0073 & 0.0060 & 0.0050 \\
at 675 nm & JJA & 0.0086 & 0.0080 & 0.0062 & 0.0060 & 0.0064 & 0.0061 \\
& SON & 0.0103 & 0.0096 & 0.0085 & 0.0082 & 0.0093 & 0.0083 \\
SSA at 675 nm & DJF & 0.0131 & 0.0102 & 0.0107 & 0.0121 & 0.0115 & 0.0088 \\
& MAM & 0.91 & 0.92 & 0.93 & 0.93 & 0.94 & 0.95 \\
& JJA & 0.92 & 0.93 & 0.95 & 0.95 & 0.95 & 0.96 \\
& SON & 0.90 & 0.91 & 0.93 & 0.94 & 0.93 & 0.94 \\
& DJF & 0.88 & 0.91 & 0.91 & 0.92 & 0.92 & 0.93 \\
\hline
\end{tabular}


Table 3

The list of the input variables used to calculate the look-up table.

\begin{tabular}{lcl}
\hline Variable name & No. of entries & Entries \\
\hline SZA & 8 & $0,10, \ldots, 70$ \\
SAZA & 8 & $0,10, \ldots, 70$ \\
RAA & 19 & $0,10, \ldots, 180$ \\
AOD & 9 & $0.0,0.15,0.45,0.8,1.2,1.6,2.6,4,5$ \\
Surface reflectance & 4 & $0.0,0.1,0.2,0.3$ \\
Surface elevation & 2 & $0 \mathrm{~km}, 4 \mathrm{~km}$ \\
\hline
\end{tabular}

of aerosol reduces the TOA reflectance by absorbing the upwelling radiance from the surface, while the increase of aerosol has a positive contribution to TOA reflectance over a dark surface. There exists, therefore, the surface reflectance at which the aerosol contribution to the TOA reflectance changes from positive to negative. The surface reflectance is called the critical reflectance (Castanho, Martins, \& Artaxo, 2008). As the SSA increases, more upwelling radiance is required to balance between backscattering and absorbing effects of aerosol in the fixed AOD condition. For that reason, the critical reflectance increases with SSA.

To apply the critical reflectance method, first of all, the sensitivity of the critical reflectance to the SSA was simulated by the 6S with five SSA conditions (SSA $1=0.77$, SSA $2=0.83$, SSA $3=0.88$, SSA $4=0.93$, and SSA5 $=0.97$ ), and the relationship between the two variables is shown in Fig. 3 with its mean and standard deviation (1-sigma). The mean and standard values are shown as closed circles and error bars, respectively. When considering the geometry of the COMS measurements, the critical reflectance was calculated for the scattering angle between $120^{\circ}$ and $180^{\circ}$.

In the satellite measurements, the critical reflectance can be obtained by a linear regression between the TOA reflectance values measured for clean and polluted conditions. Clean condition reflectance (Fig. 4(a)) was estimated by the minimum TOA reflectance for the previous 30 days at each pixel, and the measured TOA reflectance was regarded as the polluted condition reflectance (Fig. 4(b)). An area of $120 \times 120 \mathrm{~km}\left(30 \times 30\right.$ pixels, latitude $=\left[21.96^{\circ} \mathrm{N}\right.$ to $\left.23.18^{\circ} \mathrm{N}\right]$, longitude $=\left[113.20^{\circ} \mathrm{E}\right.$ to $\left.\left.114.56^{\circ} \mathrm{E}\right]\right)$ near Hong Kong was selected, which was then divided into $6 \times 6$ tiles with $25(5 \times 5)$ pixels each. Then, using a scatter plot of the TOA reflectance, as shown in Fig. 4(c), the critical reflectance was obtained from the intersection (closed circle) of the regression line (solid) and the one-to-one line (dotted) by definition. From the critical reflectance and its relationship with the SSA in Fig. 3, an aerosol type was selected among the five SSA conditions for each tile based on the selected critical reflectance. To assure the quality of the retrieved information, tiles that had any of the following

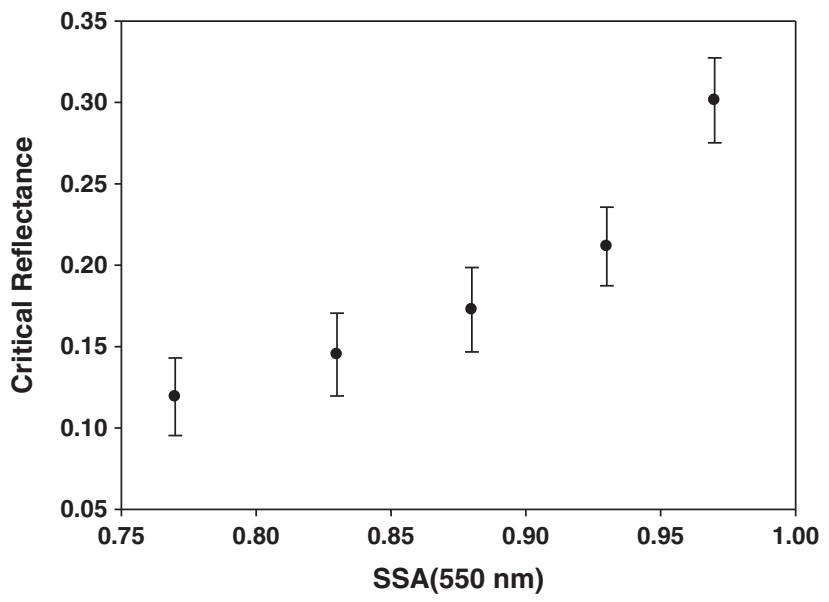

Fig. 3. Calculated critical reflectance for the five values of SSA at $550 \mathrm{~nm}$. The values of critical reflectance are simulated for the geometry of the MI measurement using the radiative transfer model 6S. conditions were excluded: (1) a determination coefficient lower than 0.7 , (2) a number of cloudy pixels greater than $50 \%$ of the total, (3) a root mean square error (RMSE) greater than 0.006 between the data points and the fitting results, (4) a slope of the fitting line greater than 1 , and (5) an effective path radiance less than 0.02 . This radiance, the $\mathrm{y}$-intercept value of the fitting line, was about 10 times the AOD difference between clean and polluted days (Zhu, Martins, \& Remer, 2011). After the quality assurance test, the aerosol types were selected by the critical reflectance method for $5.6 \%$ of the total clear pixels for the full spatial domain over the whole evaluation period. For the tiles where the critical reflectance could not be identified, the aerosol type was assumed according to the seasonal mean SSA over Hong Kong.

Because the number of the retrieved SSA was not sufficient, the accuracy of the obtained SSA from the critical reflectance is not shown here. According to Zhu et al. (2011), 88\% of the SSA retrieved from the critical reflectance method have a smaller difference than 0.03 with AERONET measurements. As an uncertainty test of the critical reflectance method, the previous study showed that the change of BOD from 0.1 to 0.3 leads to an increase of the critical reflectance by 0.005 when the AOD is 0.5 on the polluted day. Also, the SSA difference between clean and polluted days adds uncertainty in the critical reflectance determination. However, the previous study suggested that those uncertainties are within the acceptable range. Therefore, the persistent background aerosol floating may affect the accuracy of the critical reflectance, but it was not considered in this study.

\subsection{Surface reflectance retrieval}

Prior to the AOD retrieval, the surface reflectance needs to be estimated in order to distinguish the aerosol signal from the measured TOA reflectance. For estimating the surface reflectance, the clear sky composite method was adopted to take advantage of the geostationary observation. The composite method determined the surface reflectance by finding the minimum value from the Rayleigh- and gas-corrected reflectance values over the previous 30 days at a given pixel. A search window was selected to ensure the probability to find a clear day in the region using the satellite dataset.

The contribution of the surface and atmosphere can be presented as Eq. (1) by Fraser and Kaufman (1985):

$I_{\text {meas }}=I_{0}+T \cdot R /\left(1 \cdot S_{b} \cdot R\right)$

where $I_{\text {meas }}$ is the measured TOA reflectance, $I_{0}$ is the atmospheric reflectance with the Rayleigh and aerosol scattering effect, $S_{b}$ is the hemispheric reflectance, $T$ is the atmospheric transmittance for the geometry of the sun's illumination and satellite viewing, and $R$ is the surface reflectance. For the aerosol free condition, $I_{0}$ is equal to the Rayleigh scattering. By rearranging Eq. (1), the surface reflectance is expressed as a function of the $I_{\text {meas }}, I_{0}, S_{b}$, and $T$ as follows in Eq. (2):

$R=\left(I_{\text {meas }}-I_{0}\right) /\left(T+S_{b}\left(I_{\text {meas }}-I_{0}\right)\right)$.

Eq. (2) shows that the surface reflectance can be obtained by correcting the atmospheric effects from the measured TOA reflectance. However, the $I_{0}, S_{b}$, and $T$ cannot be retrieved with the satellite measurement. For this reason, they were calculated from the 6S assuming background aerosol condition, and applied to Eq. (2) regardless of the presence of aerosol. Because the background aerosol condition was assumed instead of the actual aerosol condition for the measured scene in the atmospheric correction, the calculated values are represented as $I_{0}{ }^{\prime}, S_{b}{ }^{\prime}$, and $T^{\prime}$ in Fig. 1, and the obtained result from Eq. (2) is defined as semi-surface reflectance, $R^{\prime}$. Over dark surfaces, the underestimation of the aerosol scattering effect causes the increase of semi-surface reflectance. Therefore, the minimum value among the 30 day $R^{\prime}$ values was regarded as the surface reflectance under the assumption that 

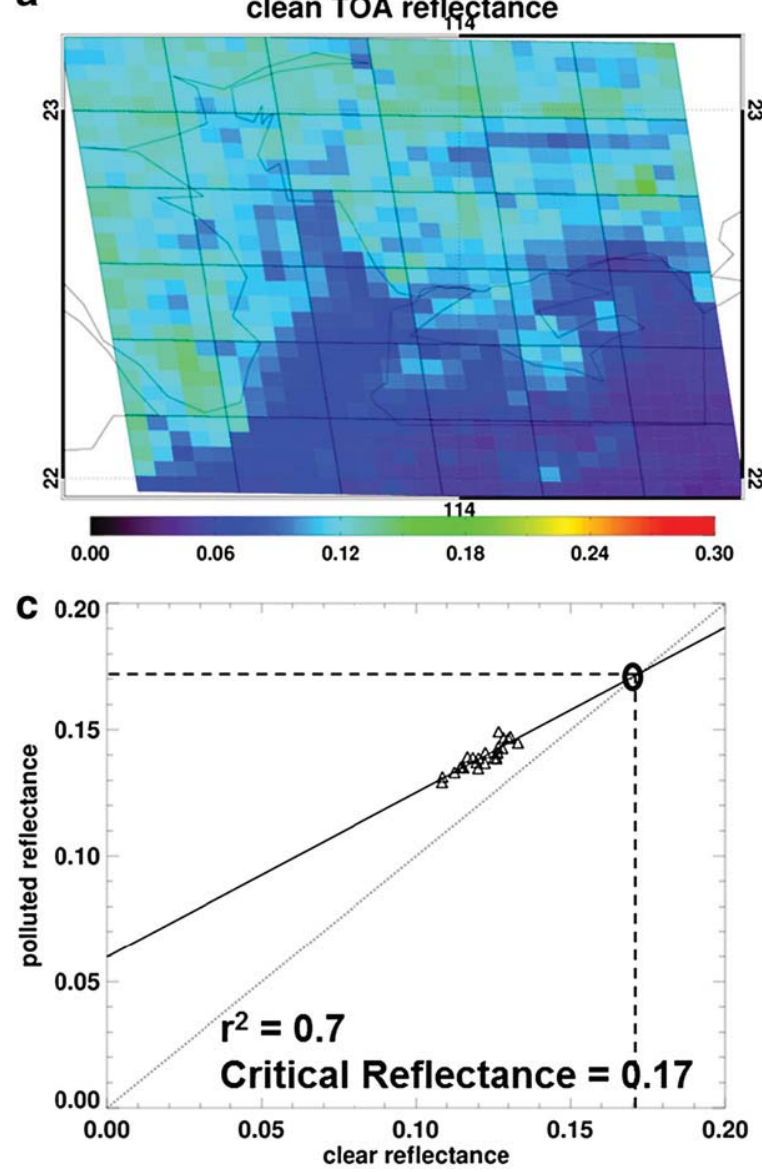

b

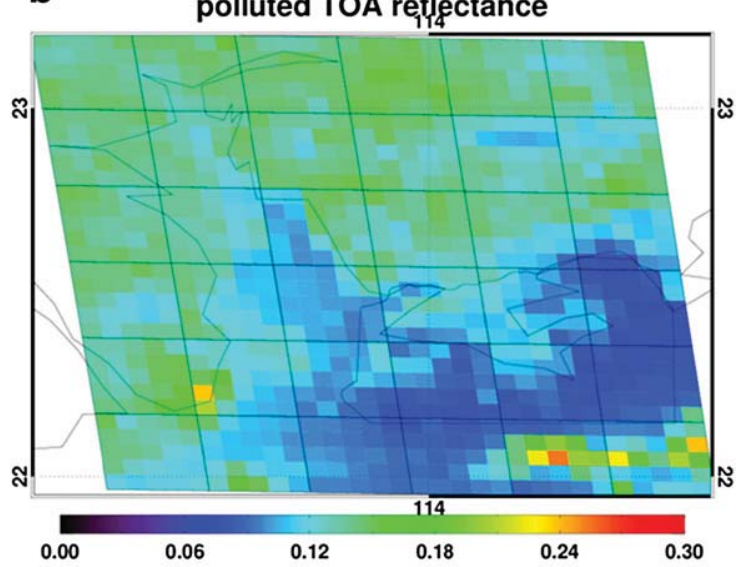

d

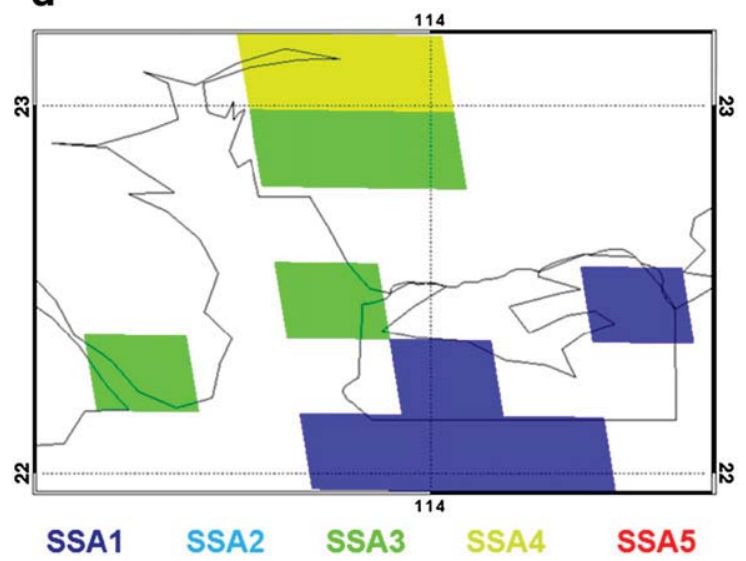

Fig. 4. TOA reflectance images of (a) clean and (b) polluted conditions. The image is divided into $6 \times 6$ tiles, and 25 values of the TOA reflectance at each tile are compared to calculate critical reflectance. The intersection of the one-to-one line (thin solid line) and the regression line (thick solid line) in the (c) scatter plot indicates the critical reflectance. Using the calculated critical reflectance, (d) the SSA is selected for each tile. SSA1, SSA2, SSA3, SSA4 and SSA5 indicate the representative SSA values of $0.77,0.83,0.88,0.93$ and 0.97 , respectively.

there was at least one clear condition without clouds and/or aerosol for each pixel.

The estimated surface reflectance by the clear sky composite method showed a reasonable pattern representing the desert, dark vegetation, and urban areas over East Asia. The turbid water reflectance over the west of the Korean Peninsula and downstream of the Yangtze River was well detected as well. However, the reflectance signal near the critical reflectance lost sensitivity to changes in the aerosol loading, and the signal began to decrease with an increase in the AOD where the surface reflectance was greater than the critical reflectance (Hsu et al., 2004). Therefore, the clear sky composite method was inapplicable to bright surfaces in this case. The seasonally averaged SSAs over East Asia including Hong Kong, which are shown in Section 2.1 and 2.3, were generally larger than 0.9 . According to the simulated relationship between SSA and the critical reflectance in Fig. 3, the critical reflectance was higher than 0.2 within the typical SSA range. Based on that reason, the pixels with a surface reflectance value higher than 0.2 were masked out during the AOD retrieval in order to avoid the uncertainty in surface reflectance.

Over the ocean, the uncertainty in estimating the surface reflectance is relatively small because the ocean surface is dark and homogeneous in general except in high wind conditions. However, the estimation of the reflectance of land surfaces is difficult due to the large temporal and spatial variation of surface type and its bidirectional nature at each pixel. Vegetation change during the search window is especially a limitation for the clear sky composite method. According to the MODIS NDVI product (MOD13C1-Lv.3) during 2012, the vegetation index increased from April to July and steadily decreased from August to December. Over the Anmyeon area, a coastal background site in Korea, the maximum increase and decrease of the NDVI during a 16day period was 0.12 in May and 0.10 in December. The values over Beijing and Seoul also represented a similar variation. Meanwhile, the NDVI and the surface reflectance at $0.66 \mu \mathrm{m}\left(R_{0.66}\right)$ in the MODIS aerosol product (MYD04-Lv.2) showed linear regression as $R_{0.66}=0.08$ 0.09 .NDVI with a correlation coefficient of 0.87 . The relationship indicates that the 0.1 increase of the NDVI corresponded to the 0.009 decrease of the $R_{0.66}$. As mentioned above, because $1 \%$ of surface reflectance error results in 10\% of AOD error in the low AOD condition, the vegetation change during April and December could add uncertainty in AOD retrieval. Similar to the vegetation change, solar angle change could also be one of the uncertainty sources in the surface reflectance estimation. Over the East Asia region, the solar zenith angle change during the 30-day period varies from $0.16 \%$ in January to $33.92 \%$ in September. Generally, those values are large during MAM and SON and small during DJF and JJA. To avoid the solar angle change effect, we found the minimum value of the semi-surface reflectance, which uses normalized solar reflectance instead of converting the minimum TOA reflectance to the surface reflectance.

To reduce the uncertainty generated by the change in surface property with time and to consider the non-Lambertian nature, several studies adapted a BRDF correction method such as the multi-angle implementation of atmospheric correction (MAIAC) algorithm (Lyapustin et al., 2011; Zhang et al., 2011). In this study, we made an attempt to apply the anisotropic reflectance obtained from MODIS BRDF parameters (MCD43) to the clear sky reflectance in order to correct the BRDF, but the effect was not significant. The clear sky composite for the semi- 
surface reflectance already takes into account the BRDF effect in a way, because the composite is from normalized reflectance for a fixed sunsatellite geometry. Therefore, additional BRDF correction was not applied here.

\subsection{Background aerosol}

In general, urbanized areas are steadily influenced by aerosols of both natural and anthropogenic origins, thus, background aerosol presents persistently even on clear days. According to the long-term analysis of the AOD products retrieved from both MODIS and AERONET, the background aerosol over Hong Kong is much greater than over other urban regions. The underestimation of this background aerosol in the basic algorithm results in a miscalculation of atmospheric parameters in Eq. (2) and an overestimation of the surface reflectance because the contribution of BOD is added to surface reflectance.

Fig. 5 shows the time series of the monthly and daily minimum AODs at $550 \mathrm{~nm}$ obtained from the 7 years of AERONET measurements at Hong Kong Polytechnology University [longitude $=114.18^{\circ} \mathrm{E}$, latitude $=22.30^{\circ} \mathrm{N}$ ] from 2005 to 2011 . From the measured AOD, the second minimum AOD in a given month was defined as the monthly BOD to avoid measurement noise and to reduce the temporal discontinuity of the BOD. The second minimum AOD showed an autocorrelation coefficient of 0.59 , whereas the first minimum AOD series showed a value of 0.38 . Although the average difference of 0.028 between the first and second minimum AODs was larger than the known uncertainty of 0.01 in AOD measurements from CIMEL instruments (Eck et al., 1999), the second minimum with stable time variation was preferred to avoid discontinuity in AOD retrieval.

As shown in Fig. 5, the monthly BOD over Hong Kong ranged from 0.03 and 0.3 , while the assumed BOD in several previous studies ranged from 0 to 0.03 (e.g., Kim et al., 2008; Knapp, Frouin, Kondragunta, \& Prados, 2005; Wong et al., 2011; Yoon et al., 2007). Over Hong Kong, the southerly monsoon brings warm, moist air from the ocean and leads to frequent precipitation, while the persistent northeast monsoons in spring and winter carry pollutants from various sources over the southeastern regions of China ( $\mathrm{He}, \mathrm{Li}$, Mao, Lau, \& Li, 2006). Also, the stable atmospheric conditions resulting from the cool, dry air in spring and winter trap the local pollution for a longer time than in other seasons. For this reason, the maximum BOD value occurred in April, while the minimum value occurred in August, as shown in Fig. 5.

The underestimation of the BOD was related to the underestimation of the retrieved AOD. Accordingly, the monthly BODs were applied to

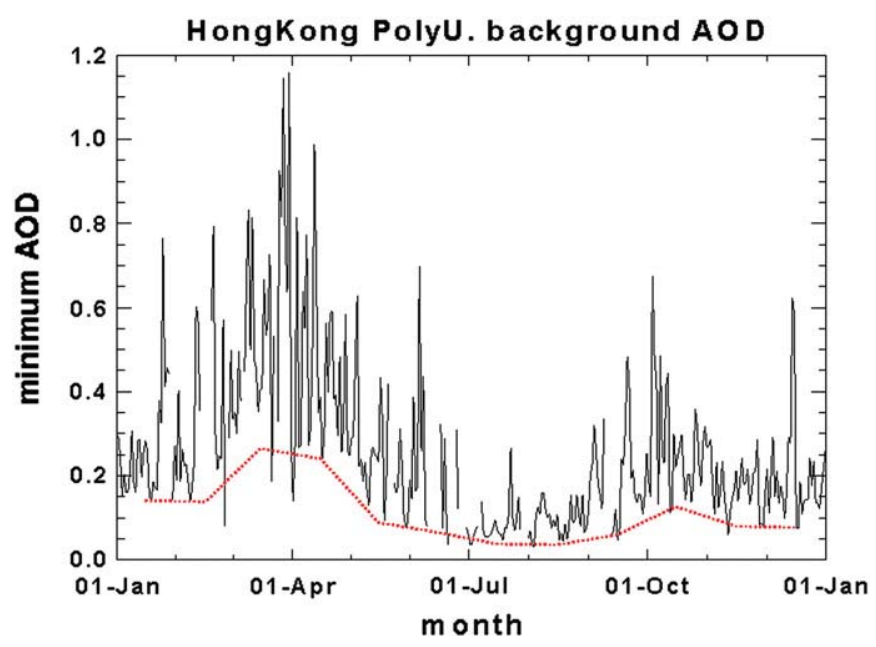

Fig. 5. Time series of the absolute minimum of the AOD at $550 \mathrm{~nm}$ obtained from 7 years of AERONET measurements at the Hong Kong Polytechnology University site from 2005 to 2011. The black solid line is the daily minimum, and the red dotted line is the monthly second minimum AOD. correct the atmospheric effects in the retrieval process of the surface reflectance over the Hong Kong region. Since the BOD generally ranges from 0 to 0.4 , as suggested by Yoon (2006), the background aerosol properties were analyzed from selected AERONET inversion data with AODs lower than 0.4 at $550 \mathrm{~nm}$. Then, the obtained aerosol properties and the BOD were applied to calculate parameters such as the $I_{0}{ }^{\prime}, T^{\prime}$, and $S_{b}{ }^{\prime}$ in Eq. (2), shown in Section 2.4, for the atmospheric correction.

\section{Results and discussion}

\subsection{Results from the basic algorithm}

The retrieved AOD over East Asia from the basic retrieval algorithm is presented in Fig. 6(b), which shows the transport of high aerosol loading from China to the Korean Peninsula. Generally, the results showed reasonable distribution varying from 0 to 3 and agreed well with the RGB image from the GOCI observation, as shown in Fig. 6(a). There was no discontinuity between the land and ocean, as the same method was applied for both regions. This algorithm also detected clean conditions even over turbid water areas, which can sometimes be mistakenly detected as having large amounts of aerosol. However, the central part of the huge dust plume in the northern part of the Shandong Peninsula was misidentified as clouds, and noise still remained near the edge of the large clouds over the China Sea, the Philippine Sea, and the south of the Pacific. Therefore, more careful attention is required to understand the effects of clouds on the retrieved AOD image and to improve the algorithm.

For the quantitative validation of the result, the retrieved AOD was compared with the value from MODIS measurements. In this study, the MODIS AOD datasets (MYD04 level2) were collocated with the criteria in time within $30 \mathrm{~min}$ and in space within $0.5 \times 0.5^{\circ}$ for validation. To avoid the remaining cloud noise, the retrieved AODs from the MI, which had lower standard deviations of the AOD than $50 \%$ of the mean AOD within the spatial collocation area, were averaged and compared to the MODIS data. The comparison result is shown in Fig. 6(c) and (d) for the period from May 2011 to May 2012 over land and ocean, respectively. The comparison results show that the performance of the single channel algorithm was reasonably good, with a correlation coefficient $(r)$ of 0.85 and 0.68 over ocean and land, respectively. However, the retrieved AOD over land was largely underestimated by about $47.3 \%$ with a higher $y$-intercept value of 0.29 compared to the reference value, while the results over the ocean were slightly underestimated by about $4.3 \%$ with a lower $y$-intercept of 0.03 . Also, the RMSE values show that the land AOD has a larger residual than the ocean AOD. As described above, the uncertainty in the surface reflectance retrieval over land results from the existence of background aerosol, which leads to the AOD underestimation, and the uncertainty is further complicated with the temporal change of surface property.

Fig. 7 compares validation results for East Asia overall and local regions of Hong Kong and Anmyeon sites. For validation, the AODs measured from AERONET over the East Asia region from May 2011 to June 2012 were collocated with the criteria in time within $30 \mathrm{~min}$ and in space within $7 \times 7$ pixels surrounding the location of the AERONET site. For East Asia, the correlation coefficient is 0.69 , and the linear regression is represented by a slope of $0.74, y$-intercept of 0.21 , and RMSE of 0.28 . Although the data frequency in the color bar represents that the retrieved AODs are well matched with the AERONET value, the scatter plot shows that the RMSE and y-intercept are significantly increased by the overestimated AOD in the range where AERONET AODs are lower than 0.5. Those overestimated AODs appeared during autumn and winter due to the increase in retrieval uncertainty related to the vegetation change and/or cloud/snow detection error.

Fig. 7(b) shows the comparison of the retrieved AOD with AERONET data at Hong Kong, and Fig. 7(c) shows the same at the Anmyeon site. Due to the data availability at the two sites in the AERONET level 2.0 inversion dataset, the period of validation is from May to October, 2011 at 
a)

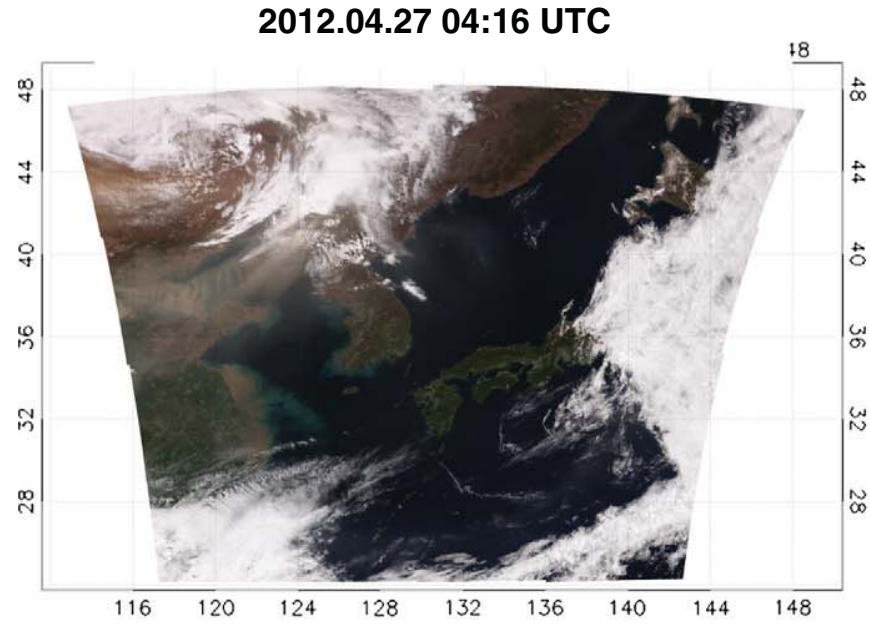

c)

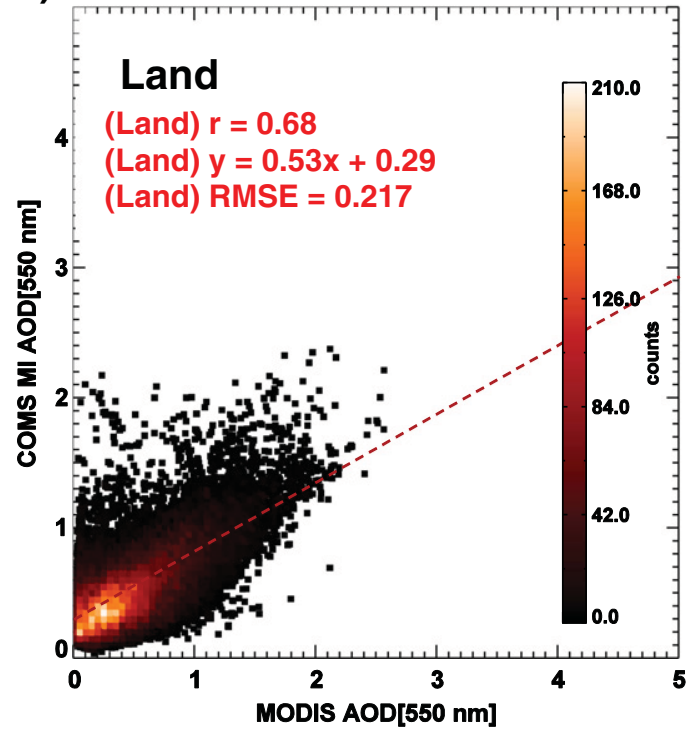

b)

MI AOD IMAGE 2012.04.27 04:15 UTC

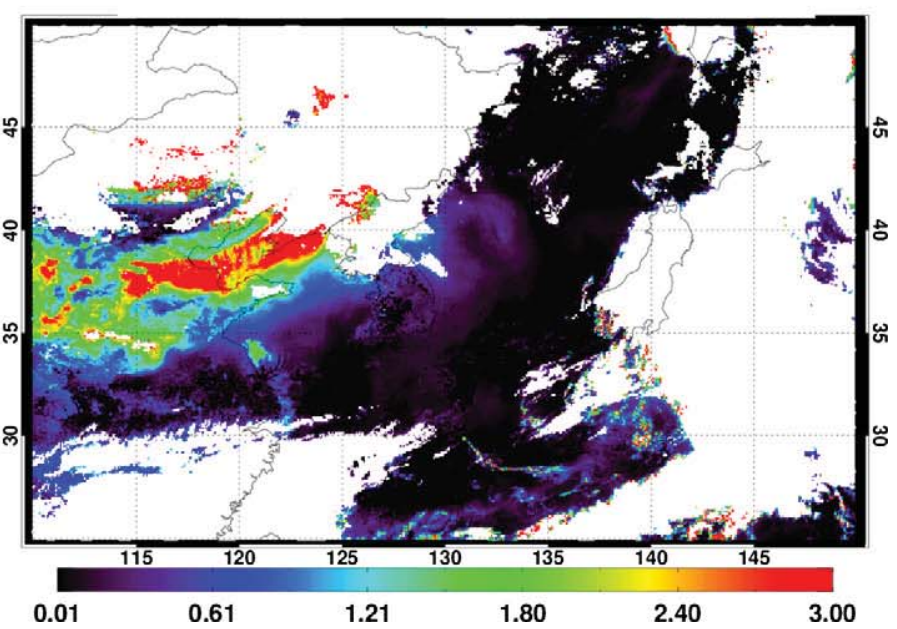

d)

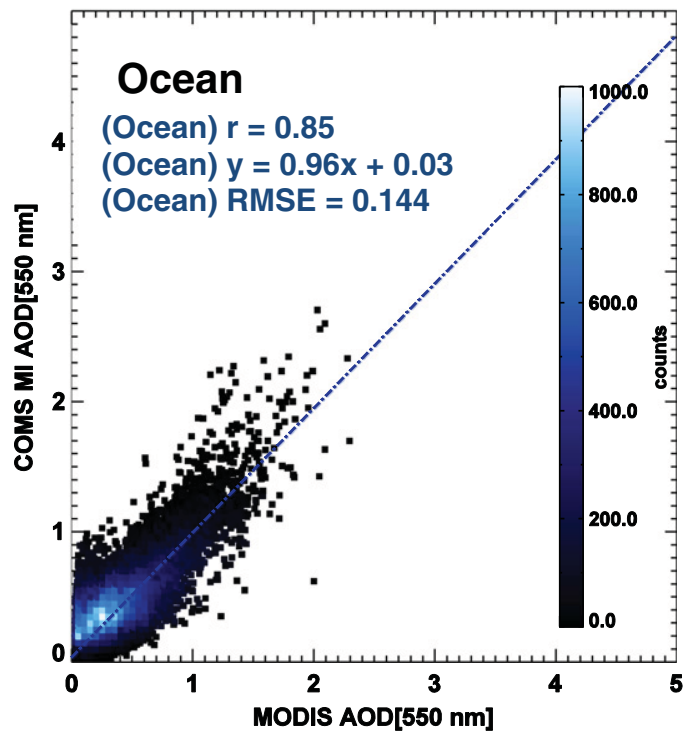

Fig. 6. An example of (a) the RGB image from GOCI and (b) the retrieved AOD at $550 \mathrm{~nm}$ from MI on April 27, 2012. The scatter plots show the relationship between retrieved AODs and the values from MODIS over (c) land and (d) ocean, respectively. The period of the comparison dataset is from May 2011 to May 2012 . The dashed line shows the linear regression and the color sale indicates the data frequency.

Hong Kong and from March to May at Anmyeon. In the case of Anmyeon, although the result might be affected by the error of surface reflectance related to vegetation growth in spring, the retrieved AODs showed agreement on the value of AERONET measurements with the correlation coefficient of 0.93 . The regression line showed that there was an overestimation tendency with a regression slope of 1.20 , yintercept of -0.08 , and RMSE of 0.11 . Whereas the retrieval accuracy was in the reasonable range at the background site, Anmyeon, the accuracy at Hong Kong was not as high for the validation, as shown in Fig. 7(b). This comparison shows that the retrieved AOD over Hong Kong was significantly underestimated. According to the MODIS NDVI product for 2012, the annual change of vegetation over the region of Hong Kong was not significant even during spring and autumn. Thus, the uncertainty caused by surface condition change was relatively low, but the uncertainty related to the determination of aerosol type and underestimated BOD is still a problem remaining over the Hong Kong area. So, the poor results could be improved by identifying the correct aerosol type and compensating the underestimated BOD, as described above.

\subsection{Comparison of improved AOD against AERONET}

The algorithm was improved by selecting the proper aerosol models using the critical reflectance and compensating for the effects of the BOD. As shown in Fig. 4(d), the SSA tended to be overestimated in the previous seasonal average models than the value determined by the critical reflectance, which resulted in a decrease in the AOD. The retrieved AOD with the critical reflectance method was validated against the AOD derived from the AERONET measurements for the same six months. Fig. 8(a) shows the validation results with a slight improvement for all of the comparison parameters, such as the correlation coefficient $(r)$, slope, and y-intercept of the linear correlation, from the values shown in Fig. 7. The first and third columns in Table 4 compare the actual values.

Using the BOD correction, the estimated surface reflectance over the dark areas decreased slightly. The change in surface reflectance not only led to an increase in the AOD over the dark regions, but also reduced the number of pixels with negative AOD. The negative AOD occurs when the summation of surface reflectance and atmospheric molecular scattering 


\section{a) East Asia}

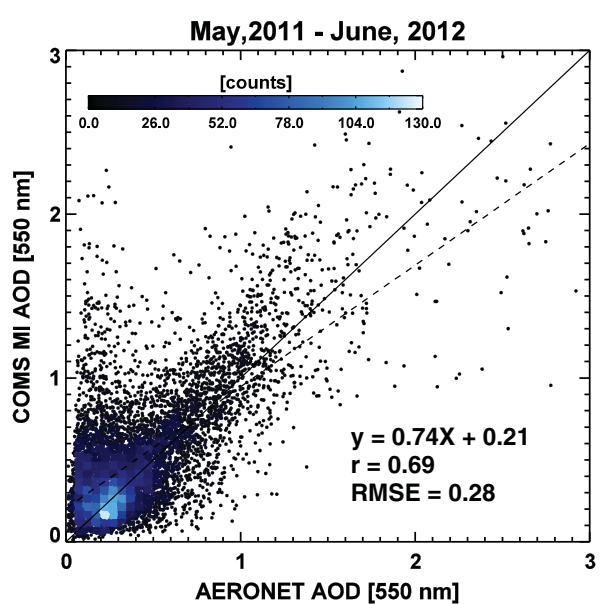

\section{b) HongKong}

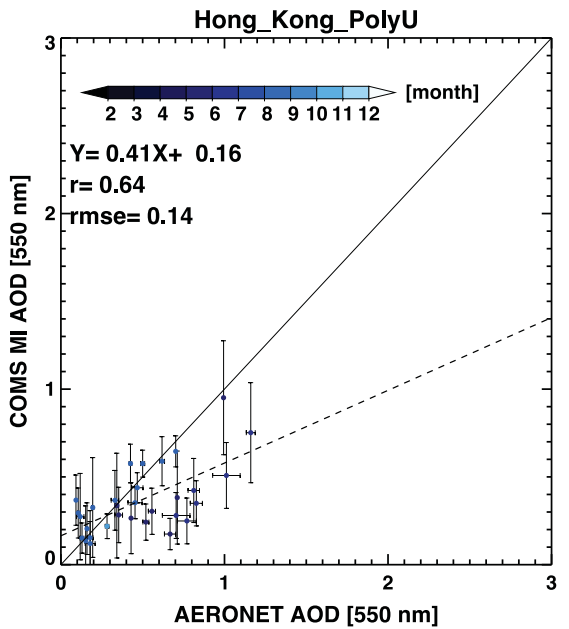

C) Anmyeon

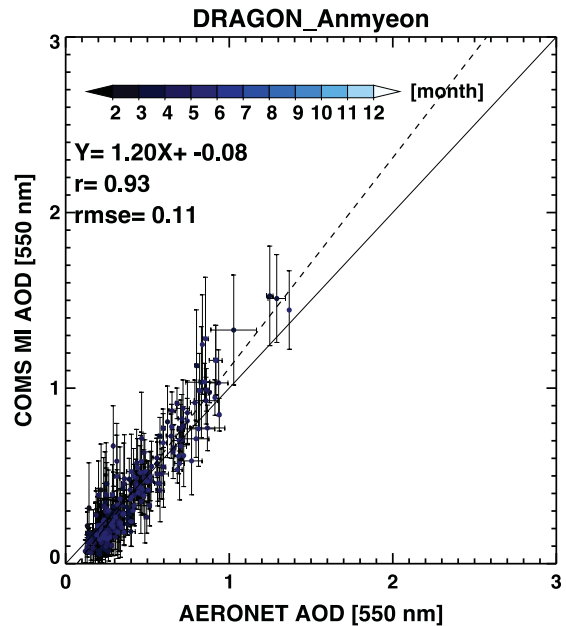

Fig. 7. Comparisons between the obtained AOD from the basic algorithm and the value from the AERONET (a) over the East Asia, (b) at the Hong Kong Polytechnology University, and (c) at the Anmyeon. The colors of the points indicate the data frequency in (a), and the month of the measurement in (b) and (c). The data period for the comparison at the Hong Kong and the Anmyeon are from May to October in 2011 and from March to May in 2012, respectively.

is larger than the measured TOA reflectance. As a result of these changes, the number of data points with a low AOD value was increased, and the linear regression between the modified AOD and AERONET values in Fig. 8(b) was improved. In this algorithm, the basic seasonal aerosol model was used instead of the critical reflectance method. Comparing Fig. 8(b) with Fig. 8(a), we can see that the improvements in the accuracy due to the BOD correction were more effective than the aerosol model correction in terms of the correlation slope and the y-intercept, while the effects of the improvement in the correlation coefficient were similar in both methods.

The retrieved AOD from the algorithm that simultaneously adopts both of the additional corrections was improved most significantly, with a correlation coefficient of 0.76 , a slope of 0.70 , and a y-offset of 0.10 , as shown in Fig. 8(c). The comparison results show that the underestimation trend was significantly reduced by adopting both methods in order to consider the heterogeneous aerosol conditions over the urbanized area, although the slope was still lower than 1. Fig. 9 shows (a) the RGB image, (b) the retrieved AOD from the MODIS measurement, (c) an example of the retrieved AOD from the MI over Hong Kong on October 18th, 2011, and (d) the scatter plot between AODs from MI and MODIS from May to October 2011. Comparing the RGB images, we can see that the localized AOD distribution over the Hong Kong area shows reasonable agreement. In addition, the retrieved AOD in higher spatial resolution of the MI measurements can provide a more detailed information about the aerosol loading over the region than the MODIS product with a spatial resolution of $10 \mathrm{~km} \times 10 \mathrm{~km}$. In the comparison of AOD with that of MODIS, the slope and y-intercept of linear regression over the ocean was better than the values over land. The comparison over land showed the linear correlation of $\tau_{\mathrm{MI}}=0.69 \tau_{\text {MoDIS }}+0.12$ with the correlation coefficient of 0.75 and was very similar to the a) Critical Reflectance method

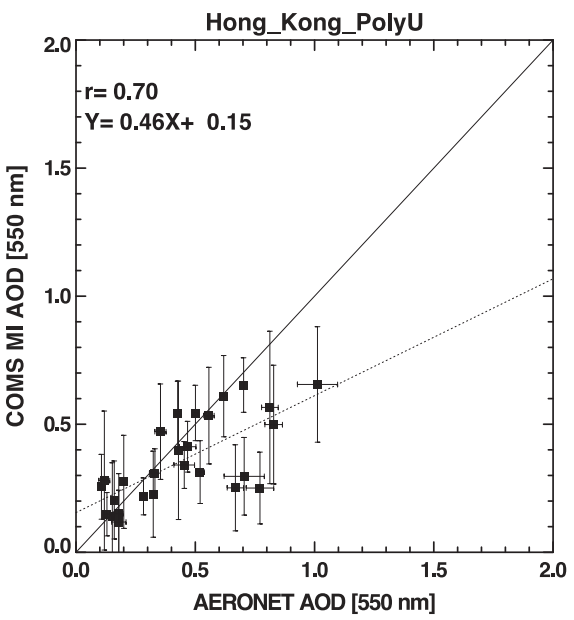

b) BOD Correction

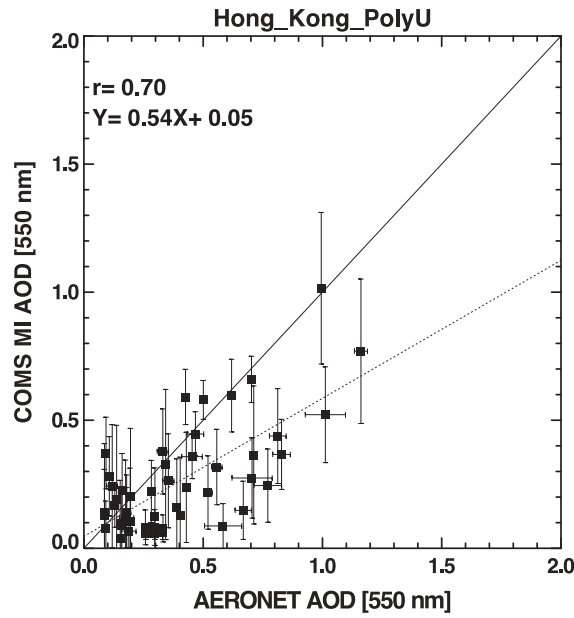

c) Both Critical reflectance method and BOD correction

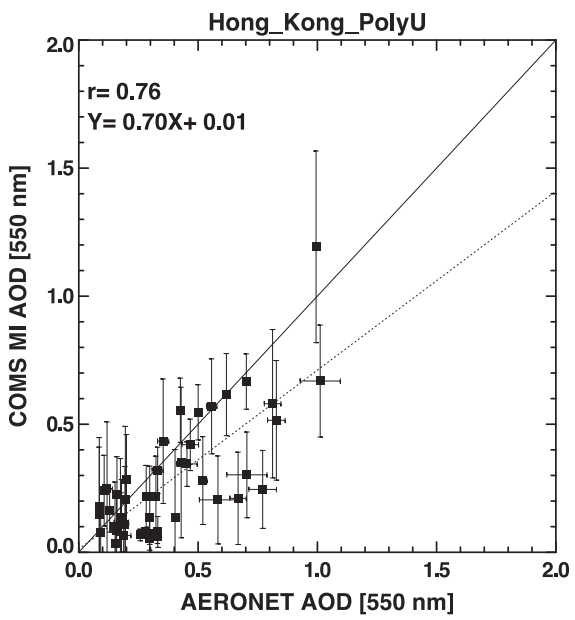

Fig. 8. Comparison between the AOD from the MI retrieval algorithm and that from the AERONET measurement for each algorithm: (a) algorithm with the critical reflectance method; (b) algorithm with background aerosol correction; (c) algorithm with both corrections. The error bar is the temporal/spatial standard deviation, and the black dotted line is the regression result. 
Table 4

Summary of the comparison results in Fig. 7 and Fig. 8.

\begin{tabular}{lllll}
\hline & Basic algorithm & Only critical reflectance & Only BOD correction \\
\hline$r$ & 0.65 & 0.70 & 0.70 & 0.54 \\
Slope & 0.41 & 0.46 & 0.76 & 0.70 \\
Intercept & 0.16 & 0.16 & 0.15 & 0.01 \\
RMSE & 0.14 & 0.12 & 0.15 \\
\hline
\end{tabular}

comparison with AERONET measurements. However, the RMSE was relatively larger than the value for the AERONET comparison.

\section{Summary}

The strength of the AOD retrieval with geostationary measurements lies in the capability to monitor the change in air quality with high temporal and spatial resolution. The capability is in particularly high demand for urbanized areas with large populations and diverse emission sources of aerosol. The aerosol loading over the localized urban area is closely related to public health and industrial activity. However, the accuracy of the AOD over the region has been relatively inferior compared to the work over dark vegetative surfaces or the ocean, because of the difficulty in considering the localized surface and atmospheric conditions. For this reason, an improved algorithm was developed to retrieve the AOD over urban areas by combining multiple techniques with a realistic dataset. In this algorithm, the presence of the background aerosol, which can be represented as a positive minimum in optical thickness,

\section{a) MODIS RGB IMAGE}

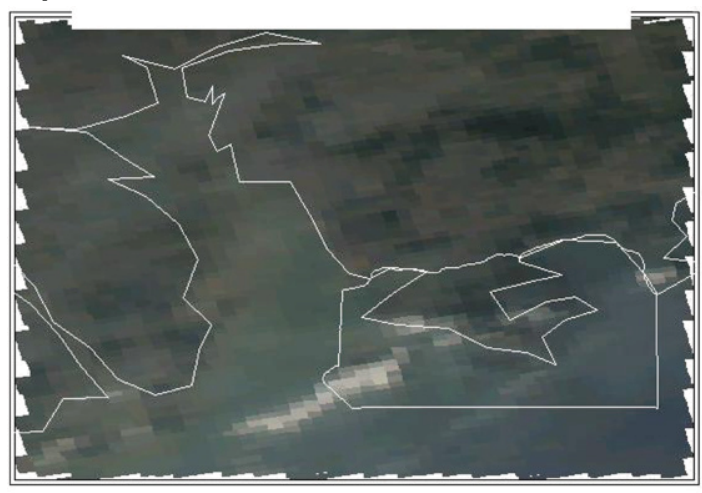

c) MODIS AOD [550 nm]

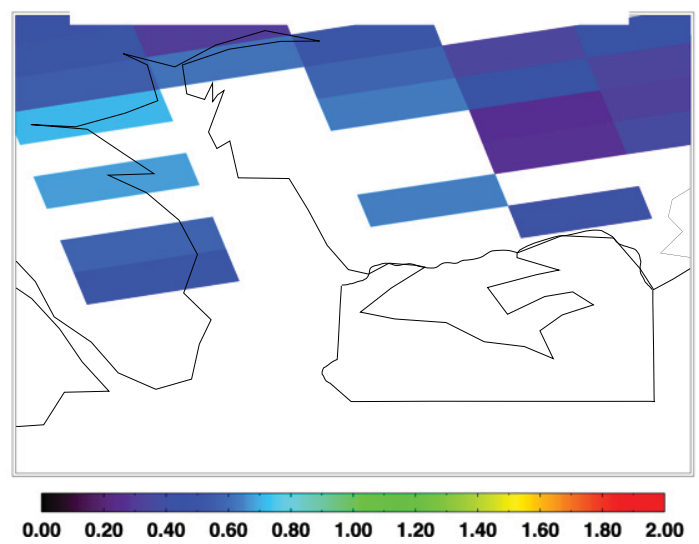

was applied to the atmospheric correction to improve the accuracy of the surface reflectance, and the critical reflectance method was adopted to select the aerosol model with only a single visible reflectance. Then, the retrieved results were validated with the measured values from AERONET.

The validation results show that the retrieved AOD over the Anmyeon area, where the BOD was relatively lower than that of the urban area, were strongly correlated with the value of AERONET, with a correlation coefficient of 0.93 and a slope of 1.20 without additional corrections. The overestimation could be caused by seasonal vegetation change. The thin cirrus clouds and cloud shadows, which were difficult to mask except by using very high resolution thermal images, were an additional source of uncertainty in the current AOD retrieval. Over Hong Kong, however, the retrieved AOD was significantly underestimated, while the comparison results over the background area were slightly overestimated. The underestimation was primarily caused by the misidentification of the aerosol type and a lack of background aerosol information in the basic algorithm. The assumed aerosol model in the basic algorithm
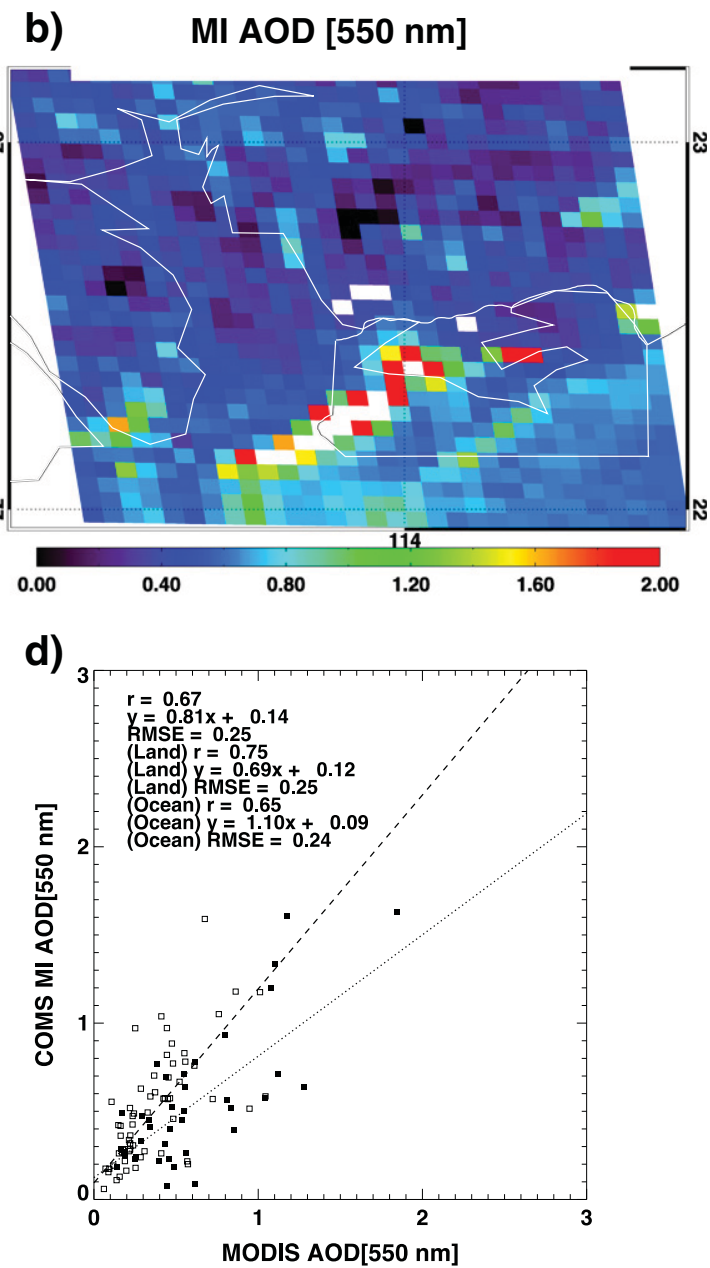

Fig. 9. An example of (a) the MODIS RGB image, (b) the retrieved AOD product with additional corrections, and (c) the MODIS level 2 AOD product over Hong Kong on October 18th, 2011 at 05 UTC. (d) is a scatter plot between AODs from MI and MODIS from May to October in 2011. The black squares are results over land and white squares are results over ocean. 
cannot represent the conditions in Hong Kong, because more than 70\% of the AERONET data set used to estimate the seasonal aerosol model was measured in Northeast Asia. In the comparison of the local aerosol optical properties over Hong Kong, the local SSA was consistently lower than the seasonally assumed value, although the increase in the SSA in summer, related to monsoon conditions, was well matched. These disagreements in the aerosol model may have resulted in the underestimation of AOD. In addition, owing to the steady local pollutant emissions, aerosol transport by the northeast monsoons, and sea salt from the south ocean, Hong Kong has the largest loading of background aerosol. Therefore, there was an obvious estimation error in the surface reflectance caused by ignoring the background aerosol.

Using the critical reflectance over Hong Kong, the SSA from the selected aerosol model was mostly lower than the value from the seasonal model, resulting from the increase in the retrieved AOD. However, the accuracy improvement by the method was marginal, because only several pixels satisfied the quality assurance test. Unnatural AOD discontinuity caused by the spatial discontinuity of the SSA model was also one of the problems with the method. In addition to the critical reflectance method, the effects of the BOD correction were more obvious in the improvement of the y-offset value. The average decrease in the surface reflectance by $2.5 \%$ led to an increase in the retrieved AOD, and the new AOD was in better agreement with those of AERONET. By the effects of both of the corrections, the correlation coefficient increased from 0.65 to 0.76 , and the slope of the linear regression increased from 0.41 to 0.70 . The y-intercept decreased from 0.16 to 0.01 . Those correlation parameters indicate that the underestimation trend of the AOD over Hong Kong was significantly improved. Therefore, the algorithm for AOD retrieval developed in this study is expected to provide more accurate results over both rural and urban areas in high temporal resolution. These results can also be utilized in comparison with the results from chemistry transport models.

While the additional corrections for urban areas led to the enhancement of AOD retrieval, bright urban surfaces with large spatial variance still had uncertainty in the surface reflectance estimation, and bidirectional reflectance could be applied to overcome this problem. Also, incomplete cloud masking can produce noise signals and high AOD values near the edge of cloudy pixels, but a tight threshold for cloud detection masked out too many aerosol scenes and reduced retrieval coverage. The BT threshold test used in this study may cause a cloud detection error during the change of the seasons, and the lack of a cirrus cloud detection process caused the overestimation of AOD retrieval. Therefore, future work needs to have a more robust, accurate cloud masking method and BRDF correction.

\section{Acknowledgment}

We acknowledge the Korea Meteorological Administration (KMA) for the COMS dataset used in this work. This research was supported by the GEMS program of the Ministry of Environment, Korea and the Eco Innovation Program of KEITI (2012000160002). This research was partially supported by the Brain Korea 21 Plus for J. Kim, M. Kim.

\section{References}

Castanho, A.D.D. A., Martins, J. V., \& Artaxo, P. (2008). MODIS aerosol optical depth retrievals with high spatial resolution over an urban area using the critical reflectance. Journal of Geophysical Research-Atmospheres, 113.

Castanho, A.D.D., Prinn, R., Martins, V., Herold, M., Ichoku, C., \& Molina, L. T. (2007). Analysis of visible/SWIR surface reflectance ratios for aerosol retrievals from satellite in Mexico City urban area. Atmospheric Chemistry and Physics, 7, 5467-5477.

Diner, D. J., Abdou, W. A., Bruegge, C. J., Conel, J. E., Crean, K. A., Gaitley, B. J., et al. (2001). MISR aerosol optical depth retrievals over southern Africa during the SAFARI-2000 dry season campaign. Geophysical Research Letters, 28, 3127-3130.

Dubovik, O., \& King, M.D. (2000). A flexible inversion algorithm for retrieval of aerosol optical properties from sun and sky radiance measurements. Journal of Geophysical Research-Atmospheres, 105, 20673-20696.

Dubovik, O., Smirnov, A., Holben, B. N., King, M.D., Kaufman, Y. J., Eck, T. F., et al. (2000). Accuracy assessments of aerosol optical properties retrieved from Aerosol Robotic
Network (AERONET) sun and sky radiance measurements. Journal of Geophysical Research-Atmospheres, 105, 9791-9806.

Eck, T. F., Holben, B. N., Reid, J. S., Dubovik, O., Smirnov, A., O'Neill, N. T., et al. (1999). Wavelength dependence of the optical depth of biomass burning, urban, and desert dust aerosols. Journal of Geophysical Research-Atmospheres, 104, 31333-31349.

Fraser, R. S., \& Kaufman, Y. J. (1985). The relative importance of aerosol scattering and absorption in remote sensing. IEEE Transactions on Geoscience and Remote Sensing, 625-633.

Haywood, J. M., \& Shine, K. P. (1995). The effect of anthropogenic sulfate and soot aerosol on the clear-sky planetary radiation budget. Geophysical Research Letters, 22, 603-606.

He, Q. S., Li, C. C., Mao, J. T., Lau, A. K. H., \& Li, P. R. (2006). A study on the aerosol extinction-to-backscatter ratio with combination of micro-pulse LIDAR and MODIS over Hong Kong. Atmospheric Chemistry and Physics, 6, 3243-3256.

Higurashi, A., \& Nakajima, T. (1999). Development of a two-channel aerosol retrieval algorithm on a global scale using NOAA AVHRR. Journal of the Atmospheric Sciences, 56, 924-941.

Hsu, N. C., Tsay, S.C., King, M.D., \& Herman, J. R. (2004). Aerosol properties over bright-reflecting source regions. IEEE Transactions on Geoscience and Remote Sensing, 42, 557-569.

IPCC (2007). Climate change 2007: The physical science basis: Contribution of Working Group I to the Fourth Assessment Report of the Intergovernmental Panel on Climate Change [Solomon, Susan, Intergovernmental Panel on Climate Change, Intergovernmental Panel on Climate Change. Working Group I.]. Cambridge; New York: Cambridge University Press.

Kaufman, Y. J., Tanre, D., Remer, L. A., Vermote, E. F., Chu, A., \& Holben, B. N. (1997). Operational remote sensing of tropospheric aerosol over land from EOS moderate resolution imaging spectroradiometer. Journal of Geophysical Research-Atmospheres, 102, 17051-17067.

Kim, J., Lee, J., Lee, H. C., Higurashi, A., Takemura, T., \& Song, C. H. (2007). Consistency of the aerosol type classification from satellite remote sensing during the Atmospheric Brown Cloud-East Asia Regional Experiment campaign. Journal of Geophysical Research-Atmospheres, 112.

Kim, J., Yoon, J. M., Ahn, M. H., Sohn, B. J., \& Lim, H. S. (2008). Retrieving aerosol optical depth using visible and mid-IR channels from geostationary satellite MTSAT-1R. International Journal of Remote Sensing, 29, 6181-6192.

Knapp, K. R., Frouin, R., Kondragunta, S., \& Prados, A. (2005). Toward aerosol optical depth retrievals over land from GOES visible radiances: Determining surface reflectance. International Journal of Remote Sensing, 26, 4097-4116.

Knapp, K. R., Vonder Haar, T. H., \& Kaufman, Y. J. (2002). Aerosol optical depth retrieval from GOES-8: Uncertainty study and retrieval validation over South America. Journal of Geophysical Research-Atmospheres, 107.

Lee, J., Kim, J., Song, C. H., Kim, S. B., Chun, Y., Sohn, B. J., et al. (2010). Characteristics of aerosol types from AERONET sunphotometer measurements. Atmospheric Environment, 44, 3110-3117.

Lee, J., Kim, J., Song, C. H., Ryu, J. H., Ahn, Y. H., \& Song, C. K. (2010). Algorithm for retrieval of aerosol optical properties over the ocean from the Geostationary Ocean Color Imager. Remote Sensing of Environment, 114, 1077-1088.

Levy, R. C., Remer, L. A., Mattoo, S., Vermote, E. F., \& Kaufman, Y. J. (2007). Second-generation operational algorithm: Retrieval of aerosol properties over land from inversion of moderate resolution imaging spectroradiometer spectral reflectance. Journal of Geophysical Research-Atmospheres, 112.

Liu, Y., Park, R. J., Jacob, D. J., Li, Q. B., Kilaru, V., \& Sarnat, J. A. (2004). Mapping annual mean ground-level PM2.5 concentrations using Multiangle Imaging Spectroradiometer aerosol optical thickness over the contiguous United States. Journal of Geophysical Research-Atmospheres, 109.

Lyapustin, A., Wang, Y., Laszlo, I., Kahn, R., Korkin, S., Remer, L., et al. (2011). Multiangle implementation of atmospheric correction (MAIAC): 2. Aerosol algorithm. Journal of Geophysical Research-Atmospheres, 116.

McClatchey, R., Fenn, R., Selby, J., Volz, F., \& Garing, J. (1972). Optical properties of the atmosphere Environmental Research Papers, ARCRL-72-0497 (3rd ed.). : Air Force Cambridge Research Laboratories.

Mishchenko, M. I., Geogdzhayev, I. V., Cairns, B., Rossow, W. B., \& Lacis, A. A. (1999). Aerosol retrievals over the ocean by use of channels 1 and 2 AVHRR data: Sensitivity analysis and preliminary results. Applied Optics, 38, 7325-7341.

Oo, M. M., Jerg, M., Hernandez, E., Picon, A., Gross, B.M., Moshary, F., et al. (2010). Improved MODIS aerosol retrieval using modified vis/SWIR surface albedo ratio over urban scenes. IEEE Transactions on Geoscience and Remote Sensing, 48, 983-1000.

Remer, L. A., Kaufman, Y. J., Tanre, D., Mattoo, S., Chu, D. A., Martins, J. V., et al. (2005). The MODIS aerosol algorithm, products, and validation. Journal of the Atmospheric Sciences, 62, 947-973.

Tanre, D., Kaufman, Y. J., Herman, M., \& Mattoo, S. (1997). Remote sensing of aerosol properties over oceans using the MODIS/EOS spectral radiances. Journal of Geophysical Research-Atmospheres, 102, 16971-16988.

Torres, O., Bhartia, P. K., Herman, J. R., Ahmad, Z., \& Gleason, J. (1998). Derivation of aerosol properties from satellite measurements of backscattered ultraviolet radiation: Theoretical basis (vol 103, pg 17099, 1998). Journal of Geophysical Research-Atmospheres, 103 (23321-23321).

Torres, O., Tanskanen, A., Veihelmann, B., Ahn, C., Braak, R., Bhartia, P. K., et al. (2007). Aerosols and surface UV products from ozone monitoring instrument observations: An overview. Journal of Geophysical Research-Atmospheres, 112.

Urm, Y. -D., \& Shon, B. J. (2005). Estimation of aerosol optical thickness over East Asia using GMS-5 visible channel measurements. J. of Atmosphere, 15, 203-211.

Vermote, E. F., Tanre, D., Deuze, J. L., Herman, M., \& Morcrette, J. J. (1997). Second simulation of the satellite signal in the solar spectrum, 6S: An overview. IEEE Transactions on Geoscience and Remote Sensing, 35, 675-686. 
von Hoyningen-Huene, W., Freitag, M., \& Burrows, J. B. (2003). Retrieval of aerosol optical thickness over land surfaces from top-of-atmosphere radiance. Journal of Geophysical Research-Atmospheres, 108

Wang, J., Christopher, S. A., Brechtel, F., Kim, J., Schmid, B., Redemann, J., et al. (2003). Geostationary satellite retrievals of aerosol optical thickness during ACE-Asia. Journal of Geophysical Research-Atmospheres, 108.

Wells, K. C., Martins, J. V., Remer, L. A., Kreidenweis, S. M., \& Stephens, G. L. (2012). Critical reflectance derived from MODIS: Application for the retrieval of aerosol absorption over desert regions. Journal of Geophysical Research-Atmospheres, 117.

Wong, M. S., Lee, K. H., Nichol, J. E., \& Li, Z. Q. (2010). Retrieval of aerosol optical thickness using MODIS $500 \times 500 \mathrm{~m}(2)$, a study in Hong Kong and the Pearl River Delta region. IEEE Transactions on Geoscience and Remote Sensing, 48, 3318-3327.

Wong, M. S., Nichol, J. E., \& Lee, K. H. (2011). An operational MODIS aerosol retrieval algorithm at high spatial resolution, and its application over a complex urban region. Atmospheric Research, 99, 579-589.

Wong, M. S., Nichol, J. E., \& Lee, K. H. (2013). Estimation of aerosol sources and aerosol transport pathways using AERONET clustering and backward trajectories: A case study of Hong Kong. International Journal of Remote Sensing, 34, 938-955.

Yoon, J. -M. (2006). Effects of atmospheric and surface properties on the retrieval of AOD from geostationary satellite. (PH.D. thesis).

Yoon, J. -M., Kim, Jhoon, Lee, Jeahwa, Cho, Hi-Ku, Sohn, Byung-Ju., \& Ahn, Myung-Hwan (2007). Retrieved of aerosol optical depth over East Asia from a geostationary satellite, MTSAT-1R. Journal of the Korean Meteorological Society, 43, 133-142.

Zhang, J. L., Christopher, S. A., \& Holben, B. N. (2001). Intercomparison of smoke aerosol optical thickness derived from GOES 8 imager and ground-based sun photometers. Journal of Geophysical Research-Atmospheres, 106, 7387-7397.

Zhang, H., Lyapustin, A., Wang, Y., Kondragunta, S., Laszlo, I., Ciren, P., et al. (2011). A multi-angle aerosol optical depth retrieval algorithm for geostationary satellite data over the United States. Atmospheric Chemistry and Physics, 11, 11977-11991.

Zhu, L., Martins, J. V., \& Remer, L. A. (2011). Biomass burning aerosol absorption measurements with MODIS using the critical reflectance method. Journal of Geophysical Research-Atmospheres, 116. 